\title{
PENGARUH VARIABEL MAKRO DAN MIKRO EKONOMI TERHADAP PEMBIAYAAN BERMASALAH PADA BANK SYARIAH
}

\author{
Sigit Arie Wibowo ${ }^{a, *}$, Wahyu Saputra ${ }^{\mathrm{b}}$ \\ a,b Universitas Muhammadiyah Yogyakarta, Jalan Lingkar Selatan, \\ Kasihan, Bantul, DI Yogyakarta \\ *(sigit_arwi@yahoo.co.id)
}

\begin{abstract}
ABSTRAK
Tujuan dari penelitian ini adalah untuk mengetahui seberapa besar pengaruh variabel inflasi, Gross Domestic Product (GDP), ukuran bank (size), Financing to Deposit Ratio (FDR), Financing to Asset Ratio (FAR), dan Capital Adequacy Ratio (CAR) terhadap variabel Non Performing Financing (NPF) pada Bank Umum Syariah di Indonesia tahun 2011-2015. Subjek penelitian ini adalah Bank Umum Syariah di Indonesia. Dalam penelitian ini, total sampel sebanyak 11 Bank Umum Syariah diperoleh dengan menggunakan metode purposive sampling. Alat analisis yang digunakan adalah analisis regresi berganda. Berdasarkan hasil analisis diperoleh bahwa, PDB, ukuran, dan CAR berpengaruh secara signifikan terhadap pembiayaan bermasalah. Sedangkan inflasi, FDR, dan FAR tidak berpengaruh terhadap pembiayaan bermasalah.
\end{abstract}

Kata kunci: pembiayaan bermasalah, Bank Syariah, inflasi, ukuran bank, NPF

\begin{abstract}
The purpose of this study is to determine how much influence the variable inflation, gross domestic product (GDP), the economic size of the Bank (size), Financing to Deposit Ratio (FDR), Financing to Asset Ratio (FAR), and the Capital Adequacy Ratio (CAR) to variable Non Performing Financing NPF) in Islamic commercial banks in Indonesia 2011-2015. This research subject is an Islamic commercial bank in Indonesia. In this study a total samples of 11 Islamic commercial banks were obtained using purposive sampling method. The analytical tool used is multiple regression analysis. Based on the analysis of the obtained results that, GDP, size, and CAR significantly influence the financing problems. As for inflation, FDR, and the FAR does not have an impact on financing problems.
\end{abstract}

Keywords: financing problems, Islamic banks, inflation, the size of the bank, NPF

\section{PENDAHULUAN}

Bank sebagai r lembaga
keuangan tentunya menjalankan
fungsinya untuk menghimpun dana
dari masyarakat $\quad$ kemudian

menyalurkannya kembali ke pihak yang sedang membutuhkan dana. Hal tersebut bertujuan agar bank mendapatkan keuntungan agar kegiatan pada bank tetap berjalan 
dan dapat berkembang. Akan tetapi dalam penyaluran dananya bank dihadapkan pada risiko kredit. Bank syariah yang termasuk lembaga keuangan juga dihadapkan dengan risiko kredit yang disebut pembiayaan bermasalah yang dilambangkan dengan Non Performing Financing\{ NPF.

Pembiayaan bermasalah ini berdampak pada biaya yang ditanggung oleh bank akan semakin besar sehingga perputaran kas yang terjadi pada bank akan terganggu. Hal ini dapat berpotensi menjadi kerugian bagi bank tersebut sehingga laba yang diperolehpun akan berkurang. Yaya, dkk (2014) menyatakan penundaan pembayaran oleh nasabah pembiayaan di satu sisi dapat mengganggu bank syariah dalam operasinya dan di lain sisi merugikan nasabah penabung karena tidak jadi mendapatkan keuntungan bagi hasil yang semestinya mereka terima.

Pada tahun 2015 data yang diambil dari statistik perbankan syariah tingkat non performing financing (NPF) pada bank syariah dianggap kurang memuaskan. Hal ini dikarenakan NPF bank syariah meningkat tajam hingga menyentuh batas normal yang ditetapkan oleh Otoritas Jasa Keuangan (OJK) yaitu $5 \%$. Besaran NPF pada Bank syariah pada tahun 2015 mencapai 4,76\% tepatnya pada bulan Februari mencapai 5,10\%. Jika dinominalkan angka tersebut mencapai nilai 10 Triliun rupiah. Walaupun data terbaru di awal tahun 2017 NPF bank syariah mulai membaik, dengan melihat nilai NPF menjadi 2,77\%.

$\mathrm{Hal}$ ini menjadi kehawatiran bagi petinggi bank syariah sehingga bank syariah memerlukan perhatian yang lebih agar dapat menanggulangi pembiayaan bermasalah yang terjadi. Melihat data dari statistik perbankan indonesia, bank konvensional hanya memiliki tingkat kredit bermasalah pada tahun 2011 hingga 2015 hanya berkisar pada $2 \%$ hingga $3.5 \%$ saja. Hal ini menunjukkan bahwa tingkat kredit bermasalah pada bank konvensional cenderung lebih stabil.

$$
\text { Tingkat pembiayaan }
$$

bermasalah yang terjadi dapat disebabkan oleh berbagai faktor, seperti faktor makro ataupun mikro ekonomi yang bisa menyebabkan tinggi rendahnya pembiayaan bermasalah yang terjadi. Inflas, serta Gross Domestic Product (GDP) bisa saja memberi dampak, bukan hanya ke debitur namun juga ke kreditur sebagai penyalur dana. Inflasi merupakan kenaikan harga barang secara umum pada perekonomian secara terus menerus dari waktu kewaktu. Inflasi ini berkemungkinan 
juga berdampak kepada debitur, karena kecenderungan harga barang yang naik akan tetapi pendapatan rill masih tetap atau bahkan menurun.

Dalam menilai pertumbuhan perekonomian suatu negara, salah satunya menggunakan Gross Domestic Product atau GDP. Dengan melihat ukuran GDP pada suatu negara dapat terlihat bahwa bagaimana barang atau jasa yang dihasilkan oleh suatu negara. Jika GDP pada suatu negara baik maka kesejahteraan masyarakat bisa dianggap membaik. Dengan menyalurkan dana ke masyarakat dengan disertai peningkataan kesejahteraan masyarakat maka, pembiayaan akan cenderung menghasilkan keuntungan.

Pembiayaan bermasalah bukan hanya terjadi karena kesalahan atau kegagalan debitur sebagai peminjam dana. Melainkan juga karena dari pihak bank sendiri yang dapat menyebabkan terjadinya pembiayaan bermasalah. Jika dilihat dari faktor mikro ekonomi terdapat beberapa fakor yaitu, ukuran bank, loan to deposit ratio (LDR), loan to asset ratio (LAR), dan capacity adequecy ratio (CAR). Pada dasarnya juga ukuran perusahaan yang dicerminkan dari nilai total aset perusahaan juga memiliki nilai tambah dalam penyaluran pembiayaan perbankan, semakin besar ukuran perusahaan nilai penyaluran dana ke masyarakat juga tentunya akan semakin besar.

Dengan melihat Financing to deposit ratio, maka dapat diperlihatkan berupa perbandingan pembiayaan yang disalurkan dengan dana pihak ketiga yang diterima oleh bank. Dana pihak ketiga yang diperolah berupa dari giro, deposito maupun tabungan. Meningkatnya dana yang dihimpun bank syariah dari masyarakat belum tentu digunakan untuk meningkatkan porsi pembiayaan yang diberikan (Darma, dan Rita, 2011)

Dalam menghitung manajemen aset menggunakan financing to asset ratio, untuk mengukur kemampuan perbankan dalam menyalurkan kredit atau dana ke debitur dengan jaminan aset yang dimiliki. Dengan memiliki aset yang mencukupi untuk melakukan pembiayaan maka akan membuat bank mendapatkan keuntungan. Jika bank tidak mampu menyalurkan kredit sementara dana yang dihimpun banyak, akan menyebabkan kerugian yang dialami olah bank (Pratiwi, 2012).

Dengan memiliki kecukupan modal, bank akan memiliki kemampuan yang lebih dalam menanggung risiko kerugian terutama kerugian yang disebabkan karena risiko kredit pada bank. Serta dapat 
memberikan kontribusi yang cukup besar dalam memperoleh profitabilitas Karena dalam praktiknya perbankan mengalami resiko terutama resiko kredit maka dari itu perlunya kecukupan modal untuk membendung kerugian yang diakibatkan oleh aktiva yang beresiko.

Berdasarkan uraian di atas, peneliti melihat perlunya penelitian kembali mengenai pembiayaan bermasalah yang terjadi pada bank syariah. Berdasarkan latar belakang tersebut maka penulis akan mengambil judul "Pengaruh Variabel Makro dan Mikro Ekonomi terhadap Pembiayaan Bermasalah pada Bank Syariah di Indonesia”. Penelitian ini merupakan pengembangan dari penelitian yang dilakukan Poetry dan Sanrego (2011). Perbedaan penelitian ini adalah menambah variabel independen yaitu financing to asset ratio dan ukuran bank, fokus penelitian hanya pada bank umum syariah saja, serta mengubah tahun penelitian menjadi 2011 hingga 2015.

\section{TELAAH LITERATUR DAN}

\section{PERUMUSAN HIPOTESIS}

\section{Risiko Kredit}

Berdasarkan Peraturan Bank Indonesia No. 5/8/2003 jo Peraturan Bank Indonesia No.11/25/BI/2009 Risiko Kredit adalah risiko akibat kegagalan debitur dan/atau pihak lain dalam memenuhi kewajiban kepada bank. Ali (2006) mengamukakan:“ risiko kredit merupakan risiko kerugian yang berhubungan dengan kemungkinan bahwa suatu pihak lawan transaksi (counter party) akan gagal untuk memenuhi kewajiban -kewajibannya ketika jatuh tempo. Risiko kredit pada bank syariah disebut dengan Pembiayaan bermasalah.

\section{Pembiayaan Bermasalah}

Menurut Denda wijaya (2005:82), pembiayaan bermasalah adalah pembiayaan-pembiayaan yang kategori kolektabilitasnya masuk dalam kriteria pembiayaan kurang lancar, pembiayaan diragukan, dan pembiayaan macet. Pembiyaan bermasalah menyebabkan bertambahnya biaya yang harus ditanggung oleh bank syariah, yang hal ini akan berimbas terhadap perputaran kas pada bank yang menjadi terhambat. Sehingga laba yang didapatkan oleh bank juga menjadi berkurang.

\section{Pengaruh Inflasi terhadap \\ Pembiayaan Bermasalah}

Pada umumnya inflasi menyebabkan harga-harga barang meningkat, hal ini berkemungkinan berdampak terhadap perekonomian 
yang menjadi lesu. Karena daya beli masyarakat akan menurun serta bisnis pun akan melemah. Debitur sebagai peminjam dana akan cenderung kesulitan mengembalikan dana kepada Bank. Pada saat terjadinya inflasi beban tanggungan debitur akan semakin tinggi akan tetapi pendapatan recara rill cenderung tetap atau bahkan menurun (Febriyanti, 2015).

Pernyataan ini sesuai dengan penelitian Baboucek dan Jancar (2005), Rahmawulan (2008), dan Simon (2010), serta Poetry dan Sanrego (2011), yang menyatakan bahwa Inflasi berpengaruh positif terhadap pembiayaan bermasalah. Maka dapat disimpulkan bahwa hipotesis adalah:

$\mathrm{H}_{1}$ : Inflasi berpengaruh positif terhadap pembiayaan bermasalah pada bank syariah.

\section{Pengaruh Gross Domestic Product (GDP) terhadap Pembiayaan}

\section{Bermasalah}

Gross Domestic Product (GDP) mengambarkan tingkat aktivitas ekonomi suatu negara yaitu jumlah barang dan jasa yang diproduksi untuk sebuah pasar. Pembiayaan pada perbankan juga cenderung akan meningkat, dengan penyaluran pembiayaan yang menghasilkan keuntungan yang baik pula memberikan dampak positif terhadap debitur untuk mengembalikan uang pinjamannya dari bank. Pertumbuhan GDP yang baik akan berdampak baik terhadap kualitas pembiayaan yang disalurkan oleh bank (Davis dan Zhu, dalam Rahmawulan, 2008). Hal ini sesuai dengan penlitian Jimenez dan Saurina (2005), Soebagio (2005), Poetry dan Sanrego (2011) yang menyatakan bahwa GDP berpengaruh terhadap pembiayaan bermasalah. Maka dapat disimpulkan bahwa hipotesis adalah:

$\mathrm{H}_{2}$ : GDP berpengaruh negatif terhadap pembiayaan bermasalah pada bank syariah.

\section{Pengaruh Ukuran Bank terhadap Pembiayaan Bermasalah}

Ukuran bank merupakan besar kecilnya bank yang dicerminkan melalui total aset dan kepemilikan modal sendiri (Ranjan dan Dahl, 2003). Semakin besarnya ukuran bank, volume kredit yang diberikan oleh bank juga akan semakin besar, maka risiko yang kredit yang dihadapi oleh bank juga akan semkin besar. Resiko yang semakin besar ini berkemungkinan akan menambah pembiayaan bermasalah yang terjadi pada bank syariah. Seperti yang diungkapkan dalam penelitian Astrini (2014), Widyastuti (2016) bahwa 
semakin besar ukuran bank maka semakin besar tingkat pembiayaan bermasalah yang terjadi. Maka dapat disimpulkan bahwa hipotesis adalah:

$\mathrm{H}_{3}$ : Ukuran bank berpengaruh positif terhadap pembiayaan bermasalah pada bank syariah.

\section{Pengaruh Financing to Deposit Ratio (FDR) terhadap Pembiayaan Bermasalah}

Financing to deposit ratio atau FDR dapat mengambarkan tingkat likuiditas perbankan. Jika Bank memiliki likuiditas yang tinggi, pembiayaan bermasalah yang terjadi akan dengan mudah ditanggulangi, karena bank akan dapat dengan mudah mencairkan aset yang mereka miliki. Sebagaian bank walaupun memiliki pembiayaan bermasalah yang tinggi akan tetapi bank memiliki rasio likuiditas yang diatas rata-rata sehingga dapat teratasi (Toby dan Adolphus, 2010).

Jika suatu bank memiliki FDR yang sehat (sesuai ketentuan Bank Indonesia) menunjukkan dari jumlah dana yang tersedia dapat digunakan secara maksimal dalam bentuk kredit sebagai aset yang dianggap produktif. Pernyataan ini sesuai dengan penelitian Soebagio (2005), Diyanti (2012). Maka dapat disimpulkan bahwa hipotesis adalah:

$$
\begin{array}{rlr}
\mathrm{H}_{4}: & \text { FDR berpengaruh negatif } \\
& \text { terhadap pembiayaan } \\
& \text { bermasalah pada bank syariah }
\end{array}
$$

\section{Pengaruh Financing to Asset Ratio (FAR) terhadap Pembiayaan}

\section{Bermasalah}

Semakin tinggi financing to asset ratio atau FAR maka tingkat likuiditasnya rendah karena jumlah aset yang diperlukan untuk membiayai kreditnya makin besar. Besarnya jumlah kredit yang disalurkan akan menentukan keuntungan bank. Jika bank tidak mampu menyalurkan kredit sementara dana yang terhimpun banyak maka akan menyebabkan bank tersebut rugi (Pratiwi, 2012).

Hal ini sesuai dengan penelitian yang dilakukan Pramudita (2012), Shingjergji (2013) dan Santosa, dkk (2013) FAR berpengaruh positif terhadap pembiayaan bermasalah. Maka dapat disimpulkan bahwa hipotesis adalah:

$\mathrm{H}_{5}$ : FAR berpengaruh positif terhadap pembiayaan bermasalah pada bank syariah.

\section{Pengaruh Capital Adequacy Ratio (CAR) terhadap Pembiayaan Bermasalah.}

Modal merupakan faktor penting bagi bank untuk mengatasi 
risiko pembiayaan bermasalah yang terjadi. Soebagio (2005) menyatakan:

"Bank yang memiliki rasio kecukupan modal yang lebih tinggi cenderung memiliki pengelolaan yang baik, sehingga dapat dikatakan bahwa CAR merupakan faktor penentu moral hazard yang dapat dihindari atau tidak."

Dengan memiliki kecukupan modal bank, pembiayaan bermasalah pada bank juga akan berkurang, karena risiko yang terjadi sebelumnya sudah diperkirakan, potensi kerugian yang dialami oleh bank akan di tanggulangi jika bank memiliki rasio kecukupan modal yang baik. Sesuai dengan penelitian yang dilakukan Soebagio (2003), Poetry dan Sanrego (2011) Maka dapat disimpulkan bahwa hipotesis adalah:

$\mathrm{H}_{6}$ : CAR berpengaruh negatif terhadap pembiayaan bermasalah pada bank syariah.

\section{METODE}

\section{Objek/Subjek Penelitian}

Objek penelitian yang diambil dalam penelitian ini adalah Bank Syariah yang ada di Indonesia. Subjek penelitian ini adalah Bank Umum Syariah yang telah di pilih. Bank Umum Syariah tersebut dijadikan subjek penelitian karena pembiayaan yang terjadi pada BUS di Indonesia dianggap kurang memuaskan pada tahun 2013 hingga 2015.

\section{Jenis dan Teknik Perolehan Data}

Jenis data yang digunakan dalam penelitian ini adalah data sekunder yang diperolah dari laporan tahunan bank syariah di Indonesia tahun 2011 hingga 2015. Data variabel mikro ini diperoleh dari laporan tahunan yang dipublikasikan bank syariah melalui website resmi masing masing bank. Serta data variabel makro di data variabel makro didapatkan dari data laporan publikasi dari Bank Indonesia.

\section{Teknik Pengambilan Sampel}

Teknik pengambilan sampel dalam penelitian ini menggunakan teknik purposive sampling guna mendapatkan sampel yang sesuai dengan kriteria yang telah ditentukan. Kriterianya adalah sebagai berikut:

a. Bank Umum Syairah yang menerbitkan laporan keuangannya yang telah diaudit.

b. Bank Umum Syairah tersebut menerbitkan laporan keuangan tahunan dengan periode 2011 hingga 2015. 


\section{Definisi Operasional Variabel Penelitian}

\section{Variabel Dependen}

Pembiyaan bermasalah pada Bank syariah dicerminkan dengan non performing financing (NPF Data diperoleh dari Non Performing Financing (NPF) yang disimbolkan dengan. NPF diukur dengan menggunakan

$\mathrm{NPF}=\frac{\text { PembiayaanBermasalah }}{\text { Total Pembiayaan }} \times 100$

\section{Variabel Independen}

Penelitian ini menggunakan enam variabel independen yang terdiri dari:

Inflasi

Inflasi adalah kecenderungan dari harga-harga untuk naik secara umum dan terus-menerus. Data Inflasi merupakan data dari BPS atau dari Bank Indonesia (BI), yang diambil dari Januari 2011 hingga Desember 2015, dengan cara di lihat berapa inflasi masing-masing di akhir tahunnya.

\section{Gross Domestic Product (GDP)}

Gross Domestic Product (GDP) digunakan untuk mengukur semua barang dan jasa yang dihasilkan dalam perekonomian suatu negara dalam periode tertentu. Data diambil dari laporan pertumbuhan perkapita GDP negara Indonesia yang dipublikasikan oleh Badan Pusat Statistik, berupa data mulai dari tahun 2011 sampai 2015.

\section{Ukuran Bank (Size)}

Ukuran bank merupakan besarnya kekayaan dalam hal ini adalah total aset yang dimiliki oleh suatu bank. Ukuran bank dapat dinyatakan dalam total aset yang dimiliki bank. Ukuran perusahaan dihitung dengan rasio bank size sebagai berikut:

Bank size $=$ Total aset perusahaan

Financing to Deposit Ratio (FDR)

Financing to Deposit Ratio merupakan rasio keuangan perusahaan perbankan yang digunakan untuk mengukur perbandingan antara kredit yang diberikan pada masyarakat dengan dana yang diterima bank. Rumus yang digunakan adalah:

FDR $=\frac{\text { Total Pembiayaan }}{\text { Total Dama Pihak Ketiga }} \times 100 \%$

Financing to Asset Ratio (FAR)

Financing to Assets Ratio digunakan mengukur kemampuan bank dalam memenuhi permintaan pembiayaan dengan perbandingan jumlah aset yang dimiliki oleh bank. Rumus yang digunakan adalah:

FAR $=\frac{\text { Total Pembiayaan }}{\text { Total } \text { Aset }} \times 100 \%$ 
Capital Adequacy Ratio (CAR)

Capacity Adequecy Ratio

adalah rasio permodalan yang

menunjukkan kemampuan bank

dalam menyediakan dana untuk

keperluan pengembangan usaha dan menampung risiko kerugian dana yang diakibatkan oleh kegiatan operasi bank. Menurut Surat Edaran Bank Indonesia No. 6/23/DPNP tanggal 31 Mei 2004 CAR dapat dirumuskan sebagai berikut:

$\mathrm{CAR}=\frac{\text { Total Aset }}{\text { Aktiva Timbang Menurut Risiko }} \times 100 \%$

\section{Perumusan Model}

Penelitian ini menggunakan model analisis regresi berganda dengan menggunakan program SPSS.

Model yang digunakan adalah:

$\mathrm{NPF}=\mathrm{a}+\mathrm{b}_{1} \mathrm{I}+\mathrm{b}_{2} \mathrm{GDP}+\mathrm{b}_{3} \mathrm{BZ}+\mathrm{b}_{4} \mathrm{FDR}+$ $b_{5} F A R+b_{6} C A R+e$

Keterangan:

$\mathrm{NPF}=$ Pembiayaan bermasalah

Pada Bank syariah

a $\quad$ Nilai konstan

$$
\begin{array}{ll}
\mathrm{b} & =\text { Koefisien arah regresi } \\
\mathrm{I} & =\text { Inflasi } \\
\mathrm{GDP} & =\text { Gross Domestic Product } \\
\mathrm{BZ} & =\text { Bank Size } \\
\mathrm{FDR} & =\text { Financing to Deposit Ratio } \\
\mathrm{FAR} & =\text { Financing to Asset Ratio } \\
\mathrm{CAR} & =\text { Capacity Adequecy Ratio } \\
\mathrm{e} & =\text { Error }
\end{array}
$$

\section{HASIL DAN PEMBAHASAN}

\section{Gambaran Umum Objek Penelitian}

Peneliti menggunakan sampel seluruh bank umum syariah yang terdaftar di Bank Indonesia, yang telah menerbitkan laporan keuangan yang telah diaudit pada periode 2011 hingga 2015. Berdasarkan metode purposive sampling yang telah ditetapkan pada bab III, maka diperoleh jumlah sampel sebanyak 11 bank umum syariah yang memenuhi kriteria. Adapun pemilihan sampel adalah sebagai berikut:

Tabel 1. Prosedur Pemilihan Sampel Bank Umum Syariah di Indonesia

\begin{tabular}{cllc}
\hline No & Kriteria sampel & Jumlah \\
\hline 1 & $\begin{array}{l}\text { Bank Umum Syariah di Indonesia yang } \\
\text { terdaftar di BI tahun 2015 }\end{array}$ & 13 \\
2 & $\begin{array}{l}\text { Bank Umum Syariah di Indonesia yang tidak } \\
\text { menerbitkan laporan keuangan periode 2011 }\end{array}$ & \\
& hingga 2015 & \\
3 & Total Perusahaan Yang Dijadikan Sampel & 11 \\
4 & $\begin{array}{l}\text { Jumlah Data Sampel Yang Diolah Selama } 5 \\
\text { Tahun (2011-2015) }\end{array}$ & 55
\end{tabular}




\section{Uji Normalitas}

Uji normalitas digunakan untuk menguji apakah nilai residual yang telah distandarisasi pada model regresi berdistribusi normal atau tidak. Dalam penelitian ini menggunakan uji normalitas dengan uji Kolmogorov-Smirnov.

Tabel 2. Hasil Uji Normalitas One-Sample Kolmogorov-Smirnov Test

\begin{tabular}{ccc}
\hline & & Unstandardiz ed Residual \\
\hline $\mathrm{N}$ & Mean & 55 \\
Normal & & .0000000 \\
Parameters & Std. Deviation & .18394674 \\
Most & Absolute & .083 \\
Extreme & & \\
Differences & Positive & .083 \\
& Negative & .055 \\
Kolmogorov- & & .613 \\
Smirnov $Z$ & & .847 \\
Asymp. SUg. & \\
(2-tailed) & \\
\hline Distribution is Normal & \\
lculated from data &
\end{tabular}

Berdasarkan tabel 1 tersebut terlihat bahwa nilai Sig. (2tailed)sebesar $0,847>0,05$. Oleh sebab itu HO diterima. Hal tersebut berarti nilai residual terstandarisasi dinyatakan menyebar secara normal.

\section{Uji Autokorelasi}

Uji autokorelasi bertujuan untuk menguji apakah antara variabel pengganggu masing-masing variabel saling mempengaruhi dalam model regresi. Uji autokorelasi dalam penelitian ini dilakukan dengan pendekatan DW (Durbin-Watson).

Tabel 3. Hasil Uji Autokorelasi

\begin{tabular}{cccccc}
\hline Model & $\mathrm{R}$ & $\mathrm{R}$ Square & $\begin{array}{c}\text { Adjusted R } \\
\text { Square }\end{array}$ & $\begin{array}{c}\text { Std. Error of } \\
\text { the Estimate }\end{array}$ & $\begin{array}{c}\text { Durbin- } \\
\text { Watson }\end{array}$ \\
\hline 1 & $.535^{\mathrm{a}}$ & .287 & .197 & .1951050 .617 & .0617 \\
\hline
\end{tabular}

Berdasarkan hasil bahwa nilai DW sebesar 0,617. Nilai D-W antara 2 sampai +2 menunjukkan tidak adanya autokorelasi. Jadi, dapat disimpulkan data pada penelitian di Indonesia tidak terjadi autokorelasi.

\section{Uji Multikolinearitas}

Mengukur multikolinieritas dapat dilihat dari nilai Tolerance dan Variance Inflation Faktor (VIF). Tolerance mengukur variabilitas variabel independen lainnya. Jadi 
nilai tolerance yang rendah sama engan nilai VIF tinggi karena VIF $=$ $1 /$ tolerance. Nilai cut off yangumum dipakai untuk menunjukkan tidak adanya multikolinieritas adalahnilai tolerance $>0.10$ atau sama dengan $\mathrm{VIF}<10$.

Tabel 4. Hasil Uji Multikolinearitas Coefficients

\begin{tabular}{|c|c|c|c|c|c|c|c|c|}
\hline \multirow{2}{*}{\multicolumn{2}{|c|}{ Model }} & \multicolumn{2}{|c|}{$\begin{array}{l}\text { Unstandardized } \\
\text { Coefficients }\end{array}$} & \multirow{2}{*}{$\begin{array}{l}\text { Standardized } \\
\text { Coefficients } \\
\text { Beta }\end{array}$} & \multirow[b]{2}{*}{$\mathrm{t}$} & \multirow[b]{2}{*}{ Sig. } & \multicolumn{2}{|c|}{$\begin{array}{l}\text { Collinearity } \\
\text { Statistics }\end{array}$} \\
\hline & & B & $\begin{array}{l}\text { Std. } \\
\text { Error }\end{array}$ & & & & Tolerance & VIF \\
\hline 1 & (Constant) & 3.262 & 1.400 & & 2.330 & .024 & & \\
\hline & INT & .597 & 1.291 & .062 & .463 & .646 & .819 & 1.222 \\
\hline & GDP & $\begin{array}{c}-3.2 \mathrm{E}- \\
015\end{array}$ & .000 & -.293 & $\begin{array}{c}- \\
2.109\end{array}$ & .040 & .772 & 1.295 \\
\hline & Size & $\begin{array}{l}-5.0 \mathrm{E}- \\
015\end{array}$ & .000 & -.468 & $\begin{array}{c}- \\
3.397\end{array}$ & .001 & .782 & 1.279 \\
\hline & FDR & .063 & .100 & .108 & .628 & .533 & .499 & 2.002 \\
\hline & FAR & -.088 & .254 & -.050 & -.348 & .729 & .729 & 1.371 \\
\hline & CAR & -.749 & .290 & -.521 & $\begin{array}{c}- \\
2.579\end{array}$ & .013 & .364 & 2.749 \\
\hline
\end{tabular}

Hasil pengujian asumsi klasik ini menunjukkan bahwa pada variabel independen nilai tolerance diatas 0,1 sedangkan pada nilai VIF semua variabel independen di bawah 10. Dengan demikian data penelitian tidak terkena masalah multikolinieritas.

\section{Uji Heteroskedastisitas}

Heteroskedastisitas berarti ada varian variable pada model regresi yang tidak sama (konstan). Pada penelitian ini pengujian heteroskedastisitas menggunakan metode Uji Spearman Rho.

Hasil pengujian menunjukan bahwa nilai sig. pada masing masing variabel independen terhadap ABS_RES lebih dari 0.05. Dengan demikian tidak ada permasalahan heterokedastisitas. Dari hasil tersebut model regresi terbebas dari masalah asumsi klasik.

\section{Uji R square}

Besarnya Tabel 6 Adjusted R Square adalah 0,197 atau sebesar 19,7\%. Dapat disimpulkan bahwa pengaruh Inflasi (INF), Gross Domestic Product (GDP), Bank Size, Financing to Deposit Ratio (FDR), Financing to Asset Ratio (FAR), dan Capital Adequecy Ratio (CAR) terhadap perubahan rasio Non Performing Financing pada Bank 
Umum Syariah di Indonesia adalah $19,7 \%$, sedangkan sisanya sebesar $80,3 \%(100 \%-19,7 \%)$ dijelaskan oleh variabel-variabel lain yang tidak dimasukkan ke dalam penelitian ini.

Tabel 5. Hasil Uji Heteroskedastisitas

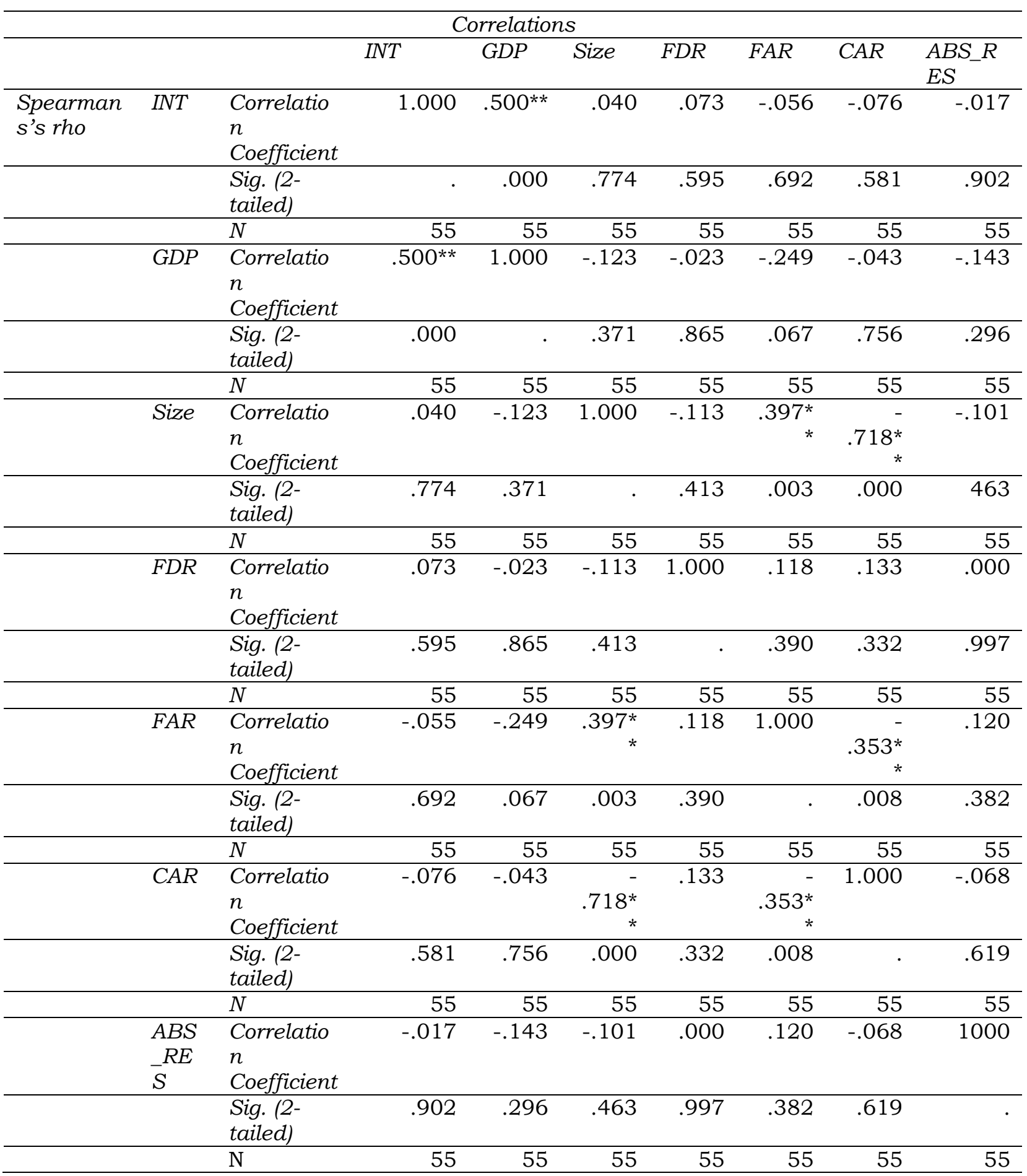


Tabel 6. Hasil Uji adjusted R Square

\begin{tabular}{|c|c|c|c|c|c|}
\hline \multicolumn{6}{|c|}{ Model Summary } \\
\hline Model & $\mathrm{R}$ & $\begin{array}{c}R \\
\text { Square }\end{array}$ & $\begin{array}{l}\text { Adjusted } R \\
\text { Square }\end{array}$ & $\begin{array}{l}\text { Std. Error } \\
\text { of the } \\
\text { Estimate }\end{array}$ & $\begin{array}{l}\text { Durbin- } \\
\text { Watson }\end{array}$ \\
\hline 1 & .535 & .287 & .197 & .1951050 & .617 \\
\hline
\end{tabular}

a. Predictors: (Constant), CAR, GDP, INT, Size, FAR, FDR

b. Dependent Variable: NPF

\section{Uji f}

dalam model mempunyai pengaruh

Uji statistik $F$ pada dasarnya secara bersama-sama terhadap menunjukan apakah semua variabel variabel dependen/terikat. independen (bebas) yang dimasukan

Tabel 7. Hasil Uji $\mathrm{f}$

\begin{tabular}{lrrrrr}
\multicolumn{6}{c}{ ANOVA } \\
\hline Model & $\begin{array}{c}\text { Sum of } \\
\text { Squares }\end{array}$ & $d f$ & $\begin{array}{c}\text { Mean } \\
\text { Square }\end{array}$ & $F$ & Sig \\
\hline Regression & .734 & 6 & .122 & 3.212 & $.010^{a}$ \\
Residual & 1.827 & 48 & .038 & & \\
Total & 2.561 & 54 & & & \\
\hline
\end{tabular}

a. Predictors: (Constant), CAR, GDP, INT, Size, FAR, FDR

b. Dependent Variable: NPF

Terlihat pada tabel $6 \mathrm{t}$ ingkat signifikan 0,010, karena tingkat signifikasi lebih kecil dari 0,05. Dapat disimpulkan bahwa variabel independen yaitu Inflasi (INF), Gross Domestic Product (GDP), Bank Size, Financing to Deposit Ratio (FDR), Financing to Asset Ratio(FAR), dan Capital Adequecy Ratio (CAR) berpengaruh secara simultan atau bersama-sama terhadap variabel dependen yaitu Non Performing Financing (NPF).
Uji t

Uji $t$ pada dasarnya menunjukan apakah semua variabel independen atau bebas secara individual dapat menerangkan variasi variabel dependen/terikat.

\section{Pengaruh Inflasi terhadap \\ Pembiayaan Bermasalah}

Berdasarkan hasil pengujian yang telah dilakukan, Inflasi tidak memiliki pengaruh terhadap pembiayaan bermasalah pada bank syariah atau hipotesis ditolak. Hasi penelitian ini sesuai penelitian Poerty dan Sanrego (2011) dan Febrianti 
(2015) bahwa inflasi tidak eksternal yang menyebabkan berpengaruh terhadap variabel perubahan-peruhanan dalam hal pembiayaan bermasalah.

Pada bank syariah pembiayaan yang disalurkan sudah memiliki akad sejak awal sehingga pengaruh tertentu tidak akan mengubah jumlah kewajiban nasabah kepada bank, sehingga debitur akan membayar sesuai akad diawal.

Tabel 8. Hasil Uji t

\begin{tabular}{|c|c|c|c|c|c|}
\hline \multirow[b]{2}{*}{ Model } & \multicolumn{2}{|c|}{$\begin{array}{l}\text { Unstandardized } \\
\text { Coefficients }\end{array}$} & \multirow{2}{*}{$\begin{array}{c}\begin{array}{c}\text { Standardize } \\
d \\
\text { Coefficients }\end{array} \\
\text { Beta }\end{array}$} & \multirow[b]{2}{*}{$t$} & \multirow[b]{2}{*}{ Sig } \\
\hline & $B$ & Std. Error & & & \\
\hline (Constant) & 3.262 & 1.400 & & 2.330 & .024 \\
\hline INT & .597 & 1.219 & .062 & .463 & .646 \\
\hline GDP & $-3.2 \mathrm{E}-015$ & .000 & -.293 & -2.109 & .040 \\
\hline SIZE & $-5.0 \mathrm{E}-015$ & .000 & -.468 & -3.397 & .001 \\
\hline FDR & .063 & .100 & .108 & .628 & .533 \\
\hline FAR & -.088 & .254 & -.050 & -.348 & .729 \\
\hline CAR & -.749 & .290 & -.521 & -2.579 & .013 \\
\hline
\end{tabular}

a. Dependent Variable: NPF

\section{Pengaruh Gross Domestic Product (GDP) terhadap Pembiayaan}

\section{Bermaslah}

Berdasarkan hasil pengujian yang telah dilakukan, gross domestic product berpengaruh negatif terhadap pembiayaan bermasalah pada bank syariah atau hipotesis diterima. Hasil penelitian ini mendukung penelitian Jimenez dan Saurina (2005), Soebagio (2005), Poetry dan Sanrego (2011) bahwa gross domestic product berpengaruh negatif dan signifikan terhadap variabel pembiayaan bermasalah. Secara jangka panjang saat aktivitas ekonomi meningkat maka pendapatan masyarakat akan naik yang pada akhirnya meningkatkan pula kapasitas bagi peminjam dana atau debitur untuk mengembalikan pinjamannya. Saat pertumbuhan ekonomi meningkat permintaan pembiayaan cenderung akan meningkat, pembiayaan tersebut akan menghasilkan keuntungan yang baik.

\section{Pengaruh Ukuran Bank terhadap Pembiayaan Bermasalah}

Berdasarkan hasil pengujian yang telah dilakukan, ukuran bank berpengaruh negatif dan signifikan 
terhadap pembiayaan bermasalah atau hipotesis ditolak. Hasil penelitian ini mendukung penelitian Diyanti (2012) dan Santosa dkk (2013) bahwa bank size berpengaruh negatif dan signifikan terhadap variabel pembiayaan bermasalah.

Bank yang lebih besar tentunya juga memiliki aset yang lebih besar pula. Bank yang memiliki ukuran yang lebih besar akan cenderung memiliki sistem penanggulangan pembiayaan bermasalah yang lebih baik dari pada bank yang kecil, sehingga dapat menekan pembiayaan bermasalah yang terjadi.

\section{Pengaruh Financing to Deposit Ratio (FDR) terhadap Pembiayaan Bermasalah}

Berdasarkan hasil pengujian yang telah dilakukan, FDR tidak memiliki pengaruh terhadap pembiayaan bermasalah pada bank syariah atau hipotesis ditolak. Hasi penelitian ini sesuai penelitian Diyanti (2012) bahwa FDR tidak berpengaruh terhadap variabel pembiayaan bermasalah. FDR hanya mengambarkan sabaik-baiknya bank dalam memanfaatkan dana yang dihimpun dari masyarakat yang berupa penyaluran pembiayaan agar mendapat keuntungan, yang kemudian menjadi kewajiban jangka pendek bank untuk mengembalikannya kembali ke nasabah yang sewaktu-waktu mengambil dananya kembali.

\section{Pengaruh Financing to Asset Ratio (FAR) terhadap Pembiayaan}

\section{Bermasalah}

Berdasarkan hasil pengujian yang telah dilakukan, FAR tidak memiliki pengaruh terhadap pembiayaan bermasalah pada bank syariah atau hipotesis ditolak. Hasi penelitian ini sesuai penelitian Santosa, dkk (2014) bahwa FAR tidak berpengaruh terhadap variabel pembiayaan bermasalah. Tinggi rendahnya FAR hanya mengambarkan bagaimana kemampuan bank dalam memenuhi permintaan pembiayaan dengan aset yang dimiliki. Nilai FAR berfokus bagaimana pengelolaan aset yang baik agar dapat melakukan penyaluran pembiayaan kepada nasabah. Jika FAR tinggi atau rendah maka tidak akan berpengaruh kepada NPF karena FAR lebih berpengaruh terhadap manajemen aset bank tersebut untuk memenuhi permintaan pembiayaan

\section{Pengaruh Capital Adequacy Ratio (CAR) terhadap Pembiayaan}

\section{Bermasalah}

Berdasarkan hasil pengujian yang telah dilakukan, CAR 
berpengaruh negatif dan signifikan terhadap pembiayaan bermasalah atau hipotesis ditolak. Hasil penelitian ini mendukung penelitian Soebagio (2005) dan Astrini (2014)bahwa CAR berpengaruh negatif dan signifikan terhadap variabel pembiayaan bermasalah. CAR memperlihatkan seberapa besar jumlah seluruh aktiva bank yang mengandung risiko, yang dibiayai dari modal sendiri. Dengan memiliki tingkat lukuidasi yang baik oleh bank, maka dapat meminimalisirkan tingkat pembiayaan bermasalah yang akan terjadi.

\section{KESIMPULAN, IMPLIKASI DAN KETERBATASAN PENELITIAN}

Berdasarkan hasil penelitian diketahui bahwa terdapat pengaruh yang negatif dan signifikan antara GDP dengan pembiayaan bermasalah pada Bank Syariah di Indonesia. Pada Ukuran Bank memiliki pengaruh negatif dan signifikan terhadap perubahan nilai perubahan bermasalah pada Bank Syariah di Indonesia. Selain itu CAR juga memiliki pengaruh negatif dan signifikan terhadap pembiayaan bermasalah pada Bank Syariah di Indonesia. Sedangkan variabel inflasi, FDR dan FAR tidak memiliki pengaruh terhadap pembiayaan bermasalah pada Bank Syariah di
Indonesia. Saran untuk penelitian ini adalah penelitian selanjutnya diharapkan meneliti dengan variabel bebas lainnya yang belum pernah diteliti sebelumya seperti manajemen risiko, atau faktor internal lainnya yang lebih spesifik. Dapat membandingkan dengan negara lainnya karena perkembangan bank syariah di negara lain terutama di ASEAN juga cukup pesat

\section{REFERENSI}

Abdullah, Faisal.M. 2004. DasarDasar Manajemen Keuangan. Malang: Universitas Muhammadiah Malang

Ali, Masyhud. 2006. Managemen Resiko. Jakarta: PT Raja Grafindo Persada.

Astrini, Suli dkk 2014. "Pengaruh CAR, LDR, Dan Bank Size Terhadap NPL Pada Lembaga Perbankan Yang Terdaftar di Bursa Efek Indonesia", eJournal Bisma Universitas Pendidikan Ganesha

Babouček, Ivan dan Martin Jančar. 2005. "Effects of Macroeconomic Shocks to the Quality of the Aggregate Loan Portfolio". Czech National Bank Working Paper, Series 1/2005, Juni 2005. Czech : The Czech National Bank.

Boediono. 1990. Ekonomi Moneter. Yogyakarta:BPFE.

Darma, E S dan Rita. 2011 "FaktorFaktor Yang Berpengaruh Terhadap Tingkat Pengguliran Dana Bank Syariah", Jurnal Akuntansi dan Investasi: 
Universitas

Muhammadiyah Yogyakarta

Diyanti, Anin. 2012. "Analisis Pengaruh Faktor Internal dan Eksternal Terhadap Terjadinya Non Performing Loan (Studi Kasus Pada Bank Umum Komersial Yang Menyediakan Layanan Kredit Pemilikan Rumah Periode 2008-2011)". Diponegoro Journal of Management Vol.1 Nomor 2 tahun 2012 hal.290-299. Universitas Diponegoro, Semarang.

Febriyanti, Silvia Eka. 2015. "Analisis Pengaruh Pertumbuhan GDP, Inflasi, Bi Rate Dan Nilai Tukar Terhadap Kredit Bermasalah Pada Bank Konvensional Dan Bank Syariah". jurnal.ub.ac.id

Jimenez, Gabriel dan Jesus Saurina 2005. "Credit cycles, credit risk, and prudential regulation." Banco de Espana, January.

Poetry, Z D dan Yulizar D Sanrego 2013 "Pengaruh Variabel Makro Dan Mikro Terhadap NPL Perbankan Konvensional Dan NPF Perbankan Syariah" Islamic Finance \& Business Review, vol 6.

Pratiwi. 2012, "Analisis Kebijakan Pemberian Kredit terhadap Non Performing Loan (Studi Pada Bank Tabungan Negara (Persero), Tbk Cabang Makassar Periode 2007-2011)". Jurusan Manajemen. Fakultas Ekonomi dan Bisnis. Universitas Hasanuddin. Makassar.

Santosa, Septiono Budi, dkk. 2014 "Analisis Pengaruh LDR, Bopo, Size, LAR Dan Nim Terhadap NPL Pada BPR Konvensional Di Wilayah Jawa Tengah (Periode 2010-2012)". Jurnal Fakultas

$\begin{array}{llr}\text { Ekonomi dan } & \text { Bisnis } \\ \text { Universitas } & & \text { Jenderal } \\ \text { Soedirman. } & & \end{array}$

Simon, Arief Budiman 2010. "Analisis Dampak Terjadinya Shock Variabel Moneter Terhadap Non Performing Loan Ratio di Indonesia". Kajian Stabilitas Keuangan Bank Indonesia. No.14 Maret 2010.
Sipahutar, Augustinus Mangasa. 2007. Persoalan-persoalan Perbankan Indonesia. Jakarta: Praninta Jaya Mandiri.

Soebagio, H 2005. "Analisis FaktorFaktor Yang Mempengaruhi Terjadinya Non Performing Loan NPL Pada Bank Umum Komersial', Tesis, Universitas Diponegoro.

Todaro, Michael P dan Stephen C. Smith 2008. Pembangunan ekonomi. Edisi kesembilan. Jakarta:Erlangga.

Toby, Adolphus J, 2007. "Financial Management Modelling of The Performance of Nigerian Quoted Small and Medium-Sized Enterprises". Journal of Financial Management \& Analysis20, 1 Jan-Jun 2007: 49-68.

Widyastuti, Jelita 2016, "Pengaruh Kecukupan Modal, Inefisiensi Biaya, LDR, Dan Ukuran. Journal of Economic and Management", unisbank.

Yaya, R., Aji E. M. dan Ahim A. 2014. Akuntansi Perbankan Syariah; Teori dan Praktik Kontemporer. Edisi kedua. Jakarta: Salemba Empat 